\title{
Antiepileptic Medication During Pregnancy: Does Fetal Genotype Affect Outcome?
}

\author{
DIANE E. ATKINSON, SOPHIE BRICE-BENNETT, AND STEPHEN W. D'SOUZA
}

Division of Human Development, The Medical School, University of Manchester, Manchester, M13 OJH, United Kingdom

\begin{abstract}
Congenital abnormalities and impaired development in childhood are attributable to fetal exposure to antiepileptic drugs (AEDs). Pregnancy registries set up to obtain information about the potential risks of fetal exposure to AEDs, in particular major congenital malformations (MCMs), suggest that valproate exposure increases the frequency of congenital malformations more than other AEDs. Furthermore, follow-up studies have drawn attention to cognitive impairments in later childhood after prenatal exposure to valproate. Fetal exposure to AEDs may be influenced by drug transporting proteins in the placenta, including P-glycoprotein (P-gp), multidrug resistance protein (MRP) 1 , and breast cancer resistance protein (BCRP). Their location in the syncytiotrophoblast plasma membrane, at the interface of the maternal and fetal circulations, allows these transport proteins to efflux xenobiotics back to the mother and offers the fetus protection from medications taken during pregnancy. Genetic variations in the expression and activity of these transport proteins may influence fetal exposure to AEDs and thus the risk of teratogenicity. Identification of a hierarchy of haplotypes ranging from susceptible to protective of congenital abnormalities could assist genetic counseling, in assessing fetal risks from exposure to AEDs. (Pediatr Res 62: 120-127, 2007)
\end{abstract}

$\mathbf{M}^{\mathrm{os}}$ ost women with epilepsy have healthy children. However, hospital- or community-based studies and data collected in pregnancy registries suggest an association between an increase in birth defects and developmental disorders affecting cognitive functioning and behavior in later childhood and AEDs used during pregnancy (1-4). There are obvious safety concerns when birth defects seem more likely with exposure to certain types of AEDs and are increased with higher drug dose and polytherapy. Furthermore, poorly controlled epilepsy during pregnancy may carry risks for complications and adverse obstetric outcome (5). Therefore, the potential risk of AED teratogenesis must be balanced against those of seizures to the mother and baby for the duration of gestation. AEDs commonly considered for monotherapy are carbamazepine, valproate, phenobarbitone, and phenytoin. New AEDs introduced in the United Kingdom include vigabatrin, lamotrigine, gabapentin, topiramate, tiagabine, oxcarbazepine, levetiracetam, and pregabalin (1).

The UK Epilepsy and Pregnancy Register, established in 1996, defined an MCM as an abnormality of an essential embryonic nature present at birth or in the first $6 \mathrm{wk}$ of life (1).

Received December 1, 2006; accepted February 15, 2007

Correspondence: Diane E. Atkinson, Ph.D., Academic Unit of Child Health, Division of Human Development, St. Mary's Hospital, Hathersage Road, Manchester. M13 OJH, UK; e-mail: diane.e.atkinson@manchester.ac.uk.
The common MCMs associated with AEDs include cardiac defects, orofacial clefts, urological defects, defects of the gastrointestinal tract, skeletal abnormalities, and neural tube defects. The MCM rate among children of women with epilepsy was $4 \%$. The reasons why these infants had MCMs with exposure to AEDs while the remaining 96\% were unaffected are not clearly understood. However, there is increasing evidence that the placenta has the capability to protect the fetus from drugs and xenobiotics in the maternal circulation (6). Therefore, there may be a relationship between the protective function of the placenta and the susceptibility to birth defects in some fetuses.

Within the placenta, there are mechanisms that can influence the transfer of drugs and xenobiotics from the maternal to the fetal circulation and that may have a role in influencing drug effects on the fetus. The rate at which a drug crosses the placenta from maternal to fetal circulation depends on its physicochemical properties and the activity of transporters and drug-metabolizing enzymes expressed on the microvillous (MVM maternal facing) and basal (BM fetal facing) plasma membranes of the transporting epithelium of the placenta, the syncytiotrophoblast (7-9). The placenta expresses a range of transporters capable of drug transport, including MDR1, P-gp $(7,8)$, MRP1 and MRP2 $(7,8)$, and BCRP $(10)$. These proteins are capable of transporting a wide range of structurally unrelated compounds out of cells in which they are expressed.

A hypothesis that links a reduced level of expression of these placental transporters and AEDs prescribed during pregnancy with birth defects and neurodevelopmental impairments in later childhood opens potential avenues for research. In this review, we consider, in sequence, the studies on pregnancy outcome in epileptic women, including those from pregnancy registries relating prenatal AED exposure to the risks of MCMs and follow-up studies that suggest impaired development in later childhood. Furthermore we discuss the role of the placenta in drug transfer and its potential to protect the fetus. Understanding the mechanisms of drug transfer by the placenta could provide clues as to why some infants of epileptic mothers are vulnerable to AED exposure in utero, whereas most are protected from congenital malformations, cognitive impairment, and additional educational needs $(1,11,12)$.

Abbreviations: AEDs, antiepileptic drugs; BCRP, breast cancer resistance protein; FACS, fetal anticonvulsant syndrome; MCMs, major congenital malformations; MDR1, multidrug resistance protein; MRP, multidrug resistanceassociated protein; P-gp, P-glycoprotein; SNP, single nucleotide polymorphism 


\section{PREGNANCY OUTCOME IN EPILEPTIC WOMEN}

\section{Fetal Losses}

Fetal losses tend to vary between studies; in the UK Epilepsy and Pregnancy Register they occurred in 5.7\% of 3607 women with epilepsy (1), whereas the EURAP Study Group (13) reported one stillbirth $(0.05 \%)$ in 1950 pregnancies. In normal populations, fetal death and stillbirth rates are $0.5 \%$ and $0.42 \%$, respectively. These rates were not significantly increased with maternal epilepsy in prospective studies in the United States (14) or Finland (5). However, a multicenter study in the United Kingdom and the United States reported that fetal death rates among women prescribed carbamazepine, lamotrigine, phenytoin, and valproate were $3.6 \%, 0 \%$, $3.6 \%$, and $2.9 \%$, respectively (4).

\section{Congenital Malformations}

Fetal anticonvulsant syndrome (FACS) has been described with all the AEDs, including MCMs, minor congenital anomalies, microcephaly, cognitive impairment, intrauterine growth restriction, and infant mortality (15). In the UK Pregnancy and Birth Register, the MCM rate among women with epilepsy who did not require AEDs was 3.5\%. With monotherapy, the MCM rate was $3.7 \%$, and with polytherapy, it was $6.0 \%$ (1). The MCM rate of $6.2 \%$ after monotherapy exposure to val- proate was higher than that for carbamazepine $(2.2 \%)$ and lamotrigine $(3.2 \%)$. There was a positive dose response for lamotrigine, with an MCM rate of $5.4 \%$ when the total daily dose exceeded $200 \mathrm{mg} / \mathrm{d}$. Although this was similar to the MCM rate of $5.1 \%$ in women receiving $\leq 1000 \mathrm{mg} / \mathrm{d}$ of valproate, the MCM rate rose to $9.1 \%$ with higher doses of valproate. In small numbers of women who had monotherapy with phenytoin, gabapentin, topiramate, or levetiracetam, the MCM rates were 3.7\%, 3.2\%, 7.0\%, and $0 \%$, respectively. Higher MCM rates reported after exposure to carbamazepine, lamotrigine, and valproate as part of a polytherapy combination were $4.1 \%, 4.8 \%$, and $9.0 \%$, respectively.

In Table 1, the MCM rates from the UK Epilepsy and Pregnancy Register and those from the United States, Europe, Australia, and Japan collectively provide support for a pattern of risk of MCMs with exposure to AEDs. First, AED polytherapy consistently confers a higher risk of MCM than does monotherapy. Second, although MCM rates varied between studies for carbamazepine, phenytoin, and phenobarbitone, there were no consistent differences, whereas valproate increased the risk of MCMs in most studies. Third, among women with a history of epilepsy who did not require AEDs, MCM rates in some studies may be similar to those in the general population.

Table 1. MCM rates in the UK Epilepsy and Pregnancy Register compared with those from other studies

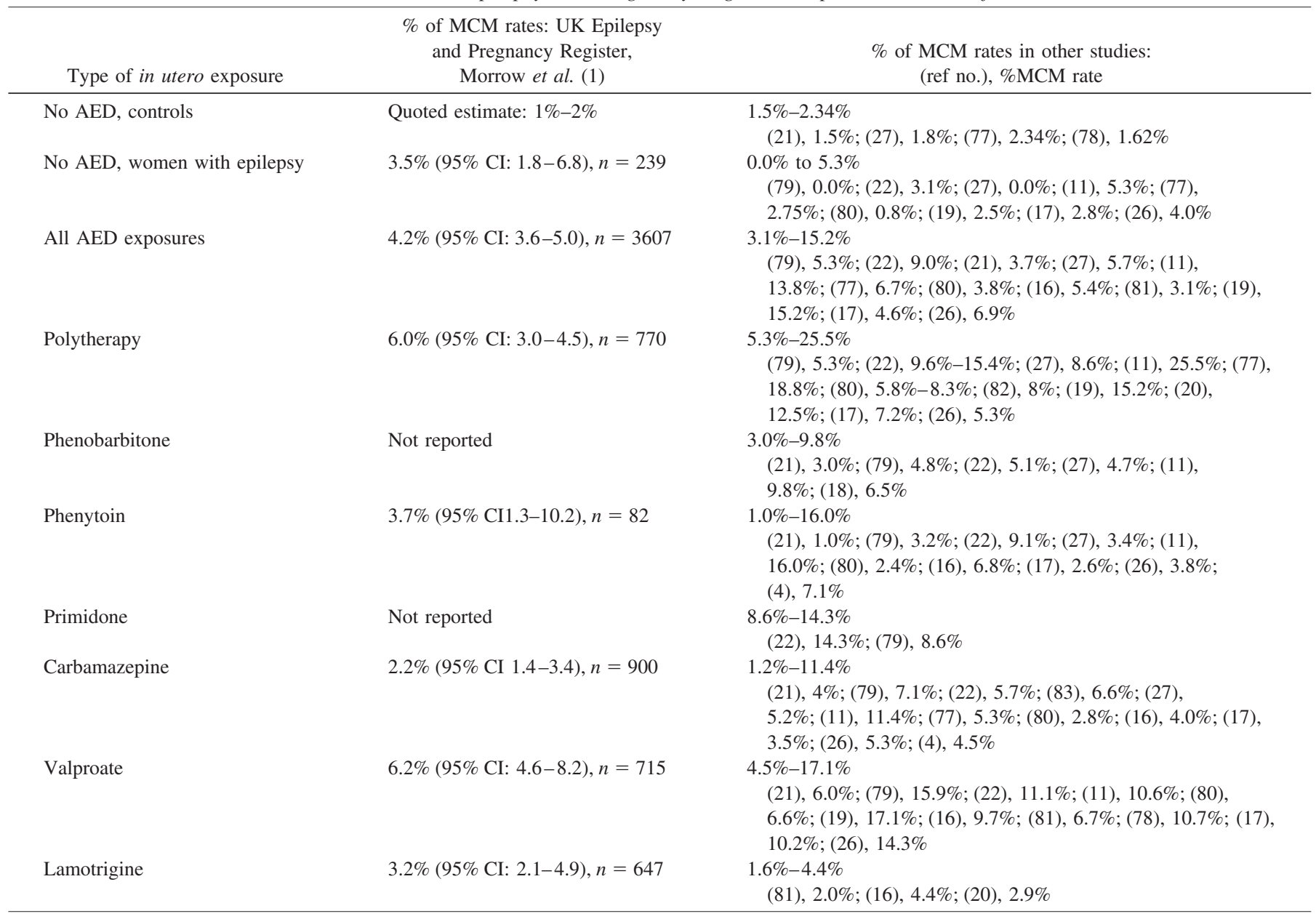


Table 2. MCMs with various AEDs (monotherapy)

\begin{tabular}{|c|c|c|c|c|c|c|c|}
\hline Drug & NTDs & Facial cleft & Cardiac & Hypospadias/GUT & GIT & Skeletal & Other \\
\hline \multicolumn{8}{|l|}{ Carbamazepine } \\
\hline Morrow et al ., 2006 (1) $(n=900)$ & $0.2 \%$ & $0.4 \%$ & $0.7 \%$ & $0.2 \%$ & $0.2 \%$ & $0.3 \%$ & $0.1 \%$ \\
\hline Kini et al., $2006(26)(n=94)$ & & $1.1 \%$ & $2.1 \%$ & & & $1.1 \%$ & \\
\hline Meador et al., 2006 (4) $(n=110)$ & & & & $3.6 \%$ & $0.9 \%$ & & \\
\hline Wide et al., 2004 (16) $(n=703)$ & $0.1 \%$ & $0.1 \%$ & $0.9 \%$ & $0.4 \%$ & $0.1 \%$ & $0.1 \%$ & \\
\hline Diav-Citrin et al., $2001(83)(n=108)$ & & $0.9 \%$ & $0.9 \%$ & $0.9 \%$ & & & $2.8 \%$ \\
\hline Samren et al., $1999(21)(n=376)$ & $0.5 \%$ & $0.2 \%$ & $1.3 \%$ & $1.06 \%$ & & $0.8 \%$ & \\
\hline \multicolumn{8}{|l|}{ Valproate } \\
\hline Morrow et al., 2006 (1) $(n=715)$ & $1.0 \%$ & $1.5 \%$ & $0.7 \%$ & $1.3 \%$ & $0.3 \%$ & $1.1 \%$ & $0.3 \%$ \\
\hline Kini et al., $2006(26)(n=63)$ & $3.2 \%$ & & & $9.5 \%$ & & $3.2 \%$ & $4.7 \%$ \\
\hline Meador et al., 2006 (4) $(n=69)$ & $1.4 \%$ & $1.4 \%$ & $5.8 \%$ & $8.6 \%$ & & $2.8 \%$ & \\
\hline Vajda and Eadie, 2005 (19) $(n=165)$ & $3.6 \%$ & $1.8 \%$ & $4.8 \%$ & $3.6 \%$ & & & \\
\hline Wyszynski et al., 2005 (78) $(n=235)$ & $1.3 \%$ & & $2.1 \%$ & $1.3 \%$ & $0.4 \%$ & $0.9 \%$ & $0.4 \%$ \\
\hline Wide et al., 2004 (16) $(n=268)$ & $0.7 \%$ & $1.5 \%$ & $2.6 \%$ & $2.6 \%$ & & $0.4 \%$ & $0.4 \%$ \\
\hline Samren et al., $1999(21)(n=158)$ & $2.5 \%$ & & $0.6 \%$ & $1.9 \%$ & & $0.6 \%$ & \\
\hline \multicolumn{8}{|l|}{ Lamotrigine } \\
\hline Morrow et al., 2006 (1) $(n=647)$ & $0.2 \%$ & $0.2 \%$ & $0.6 \%$ & $0.9 \%$ & $0.5 \%$ & $0.3 \%$ & $0.6 \%$ \\
\hline Cunnington et al., 2005 (20) $(n=414)$ & $0.2 \%$ & $0.2 \%$ & $0.7 \%$ & $0.5 \%$ & $0.7 \%$ & $0.5 \%$ & \\
\hline \multicolumn{8}{|l|}{ Phenytoin } \\
\hline Morrow et al., 2006 (1) $(n=82)$ & & $1.2 \%$ & $1.2 \%$ & & $1.2 \%$ & & \\
\hline Kini et al., 2006 (26) $(n=26)$ & & & & $3.8 \%$ & & & \\
\hline Meador et al., 2006 (4) $(n=56)$ & $1.8 \%$ & & $1.8 \%$ & $3.57 \%$ & & & \\
\hline Samren et al., 1999 (21) $(n=151)$ & $0.7 \%$ & $0.7 \%$ & & $0.7 \%$ & & & \\
\hline \multicolumn{8}{|l|}{ Phenobarbitone } \\
\hline Holmes et al., 2004 (18) $(n=77)$ & & $1.3 \%$ & $5.2 \%$ & & & & \\
\hline
\end{tabular}

NTDs, neural tube defects; GUT, genitourinary tract; GIT, gastrointestinal tract.

The frequency of MCMs associated with valproate was two to three times higher than that with carbamazepine in three registries: the Swedish registry (16), the UK registry (1), and the Finnish registry (17). Additional evidence to support an increased frequency of MCMs with valproate comes from the American registry (18), the Australian registry (19), and the International Lamotrigine Pregnancy Registry (20) without an obvious systematic bias that could have increased the frequency of MCMs with valproate monotherapy or polytherapy. Nevertheless, the possibility that carbamazepine or valproate might have been used to treat different types of epilepsy raises questions about whether the epilepsies treated or their interaction with AEDs might influence the frequency of MCMs. The findings in the UK registry that higher doses of valproate can increase MCM rates were consistent with those in other studies $(17,21-23)$ and add support for the adverse effects of valproate.

New AEDs. Preclinical studies with new AEDs in animals suggest that they carry a risk of congenital abnormalities (24). Clinical experience with the new AEDs during pregnancy is limited, except possibly with lamotrigine $(1,20)$ (Table 1$)$. In the International Lamotrigine Pregnancy Registry, the risk of all major birth defects with lamotrigine monotherapy was $2.9 \%$ (20). Exposure to lamotrigine polytherapy including valproate increased the MCM rates to $12.5 \%$, and with polytherapy excluding valproate, the $\mathrm{MCM}$ rate was $2.7 \%$. In larger numbers of women recruited for the UK Epilepsy and Pregnancy Registry with lamotrigine monotherapy, the risk of MCMs was slightly higher at 3.2\% (1). A trend for the MCM rate to increase with maternal dose $(1.3 \%$ at $<100 \mathrm{mg} / \mathrm{d} ; 1.9 \%$ at $100-200 \mathrm{mg} / \mathrm{d}$; and $5.4 \%$ at $>200 \mathrm{mg} / \mathrm{d}$ ) may imply a cause-and-effect association (20). However, this interpretation should be treated cautiously as there may be other risk factors for MCMs with higher doses including a greater severity of epilepsy.

Types of MCMs. Some MCMs are well recognized after exposure to certain AEDs. Carbamazepine and valproate exposure were associated with spina bifida and cleft lip and palate, microcephaly with phenytoin, and hypoplastic nails with phenytoin and carbamazepine. Cardiac malformations occur with exposure to any of these AEDs (3). Data on the frequency of these types of MCMs linked to fetal exposure to specific AEDs in large groups of women with epilepsy through the use of a surveillance system of infants are limited and less clear with the new drugs due to small numbers of women receiving treatment. Table 2 shows the types of MCMs after fetal exposure to AEDs in the UK Epilepsy and Pregnancy Register (1) and in other studies.

Dysmorphic features. Minor variations from normal appearance including wide-set eyes, epicanthic folds, dysplastic ears, broad nasal bridge, thin upper lip, abnormal philtrum, and distal phalangeal or nail hypoplasia can be subtle in infancy and become less apparent in older children. Similar findings among infants of women with epilepsy who did not receive AEDs raised the possibility that these anomalies were due to genetic abnormalities that caused maternal epilepsy (25). However, in a group of children aged 6 mo to $6 \mathrm{y}$ exposed to valproate during pregnancy, the features commonly recognized by an expert panel of dysmorphologists were medial deficiency of the eyebrows, infraorbital grooves, broad nasal bridge, anteverted nose, abnormal philtrum, and a thin upper lip. The commonly recognized features with carbamazepine exposure were full cheeks with a small chin and everted lower lip, giving a "doll-like" appearance (26). 
Table 3. WISC scores in children exposed to valproate or carbamazepine in utero

\begin{tabular}{|c|c|c|c|}
\hline & $\begin{array}{c}\text { VIQ } \\
\text { Mean }(95 \% \text { CI })\end{array}$ & $\begin{array}{c}\text { PIQ } \\
\text { Mean }(95 \% \mathrm{CI})\end{array}$ & $\begin{array}{c}\text { FSIQ } \\
\text { Mean }(95 \% \text { CI })\end{array}$ \\
\hline \multicolumn{4}{|l|}{ Adab et al. $(2)^{*}$} \\
\hline Valproate $(n=41)$ & $83.6(78.2-89.0)$ & $94.0(88.9-99.0)$ & $87.2(81.9-92.5)$ \\
\hline Eriksson et al. $(30) \dagger$ & Mean $(95 \% \mathrm{CI})$ & Mean $(95 \% \mathrm{CI})$ & Mean $(95 \% \mathrm{CI})$ \\
\hline Valproate $(n=13)$ & $85.1(70.2-99.9)$ & 84.7 (68.4-101.0) & $84.5(69.4-99.7)$ \\
\hline Carbamazepine $(n=13)$ & $96.5(86.9-106.0)$ & $102.5(93.7-11.4)$ & $98.9(91.2-106.5)$ \\
\hline \multicolumn{4}{|l|}{ Gaily et al. (29)末 } \\
\hline Valproate $(n=13)$ & $83.5 \pm 3.8$ & $96.3 \pm 4.8$ & $89.7 \pm 3.6$ \\
\hline Carbamazepine $(n=86)$ & $96.2 \pm 1.9$ & $103.1 \pm 1.5$ & $99.7 \pm 1.8$ \\
\hline
\end{tabular}

* Children aged 6 to $16 \mathrm{y}$.

$\dagger$ Children aged 6.6 to 13.4 y.

$\ddagger$ Preschool and school-age children.

\section{Effects on Development in Later Childhood}

Fetal exposure to AEDs at different stages of gestation may result in a variety of developmental, cognitive, and behavioral effects in later childhood (3). Children of epileptic women who did not take drugs during pregnancy have fewer cognitive problems than matched controls (27). Valproate was identified as a drug carrying potential risks for developmental delay and cognitive impairment more than other AEDs (12,28-30). Using the Wechsler Intelligence Test for Children (WISC III), children exposed to valproate in utero had a reduction in verbal IQ (VIQ) but not in performance (nonverbal) IQ (PIQ) or full scale IQ (FSIQ) (Table 3) (12). Valproate exposure had a dose-related effect with a lower VIQ among children exposed to $>800 \mathrm{mg} / \mathrm{d}$ during pregnancy than those exposed to $<800 \mathrm{mg} /$ d. More valproate-exposed children had additional educational needs, including speech therapy compared with those exposed to other AEDs or no AEDs. Similar effects were not observed among children exposed to carbamazepine (29). However, it may be that, as a group, women who used valproate during pregnancy were different from those who used carbamazepine or no AEDs as they had less education and a lower IQ (30) (Table 3). These observations thus raise a possibility that the cognitive differences in children exposed to valproate were partly inherited.

\section{ROLE OF PLACENTAL DRUG TRANSPORTING PROTEINS IN FACS}

\section{MultiDrug Resistant Epilepsy}

Evidence that MDRPs (multidrug resistance proteins) can efflux AEDs to a functionally significant extent comes from studies of multidrug-resistant epilepsy $(31,32)$. In about one third of cases, epilepsy is resistant to drug treatment and many patients who are resistant do not become seizure free with any of a broad range of AEDs. This is analogous to the MDR observed in cancer and suggests a common, nonspecific mechanism. MDR transporters at the blood-brain barrier are increasingly being recognized for their ability to modulate the absorption, distribution, and elimination of drugs. Tishler et al. (33) first described the overexpression of MDR1 in brain specimens removed from patients with intractable epilepsy, showing mRNA levels $>10$ times that in normal brain. Other studies have since reported overexpression of a range of MDR transporters in the endothelial cells that constitute the bloodbrain barrier and astrocytes in drug-resistant epileptic brain tissue. These transporters include MRP1, 2, and 5 and BCRP (34).

Studies on the AED specificities of these proteins provide further evidence that these proteins can efflux these drugs to a physiologically and clinically significant extent. Marchi et al. (35) showed that efflux of phenytoin from astrocytes isolated from epileptic tissue is greater than that from control astrocytes and that this difference is abolished in the presence of MDR1 inhibitors. Potschka et al. (36), using in vivo microdialysis showed that inhibition of MDR1 and/or MRP1 increases the concentration of phenobarbital, lamotrigine, felbamate, phenytoin, and carbamazepine in the extracellular fluid of the cerebral cortex in the rat. This group has also demonstrated that brain levels of phenytoin in MRP2-deficient mice are significantly higher than in control animals (37).

Therefore, localized to the apical membrane of brain capillary endothelial cells, MDRPs transport AEDs toward the blood compartment, thereby limiting their penetration into and retention within the brain, hence moderating effectiveness and contributing to drug resistance. In the context of FACS, differences in expression of these proteins at the maternal-fetal interface i.e. the placenta may be significant in determining fetal susceptibility.

\section{Placental MDRPs}

MDR1, $A B C B 1$. MDR1 P-gp is a member of the adenosine triphosphate (ATP) binding cassette (ABC) superfamily of transporters. This protein uses the energy from ATP hydrolysis to actively efflux a wide range of drugs and naturally occurring xenobiotics from cells in which it is expressed. Its ability to efflux a huge range of anticancer agents leads to the cross-resistance patterns seen in MDR; however, its substrate profile extends well beyond anticancer agents and it has now been established that this protein can efflux drugs from many different classes including anticonvulsants, human immunodeficiency virus protease inhibitors, antibiotics, $\mathrm{Ca}^{2+}$ channel blockers, cardiac glycosides, and immunosuppressants. 

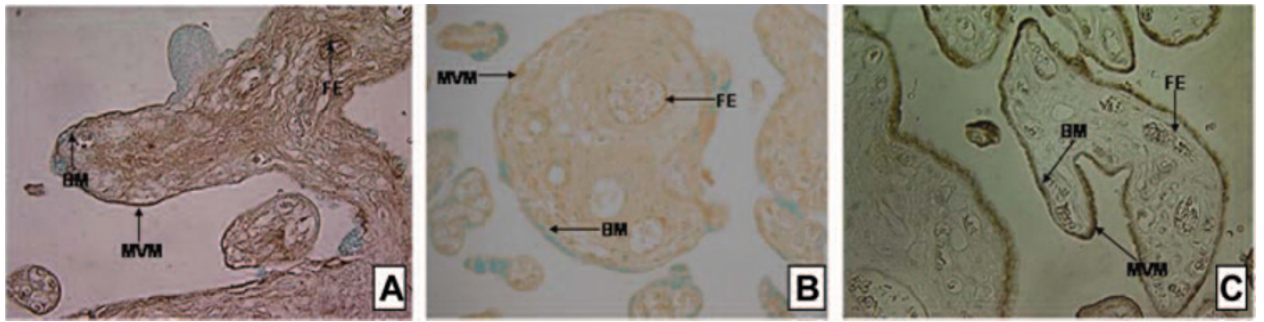

Figure 1. Expression of $\mathrm{P}$-gp ( $A$, antibody F4 1:20), MRP1 ( $B$, antibody MRPm6 $1: 20)$ and BCRP ( $C$, antibody BXP21 $1: 50)$ in term human placenta. Picture shown is representative of $n=4$ placentas; $\mathrm{FE}=$ fetal endothelium; MVM $=$ microvillous membrane; $\mathrm{BM}=$ basal membrane.

P-gp is expressed in normal tissues particularly at the sites of absorption (gut) and excretion (kidney and liver) and on blood tissue barriers (brain, testes, and placenta). Its vectorial transport capacity, together with this pattern of expression, has led to the hypothesis that this protein has evolved to protect organisms from naturally occurring xenobiotics. It is now well recognized that $\mathrm{P}$-gp affects the absorption, distribution, and elimination of many therapeutic drugs.

In line with the hypothesis that P-gp fulfills a protective role, there has recently been much interest in placental P-gp expression and function in terms of protecting the fetus from drugs and xenobiotics. It is now well established that P-gp is expressed by the placental syncytiotrophoblast throughout gestation (38) and that at term it is localized to the microvillous maternal facing plasma membrane (Figs. $1 A$ and 2) $(8,39)$. An early study by Nakamura et al. (40) established functional activity in the placenta by demonstrating P-gpmediated uptake of vincristine into syncytiotrophoblast membrane vesicles. This activity has since been confirmed using a range of placental models including choriocarcinoma cells (39) and cell monolayers (41), placental fragments (7), microvillous membrane vesicles (42), and dually perfused human placental lobules (43).

The contribution that P-gp makes to the barrier function of the placenta is best illustrated in mice naturally deficient in P-gp and in P-gp knockout mice. Studies in these animals have shown that, in the absence of placental P-gp, fetal concentrations of substrate drugs are much higher than in control animals (44). Furthermore, treatment of heterozygous females with an isomer of avermectin, a known teratogenic substrate of P-gp, results in $100 \%$ cleft palate in fetuses deficient in P-gp (-l-), whereas the heterozygotes $(+/-)$ are less susceptible and those expressing abundant P-gp $(+/+)$ are pro- tected from the effects of avermectin at the doses studied (45). Thus, P-gp has the capacity to protect the fetus from the harmful effects of drugs in the maternal circulation, and although there are no direct studies on AEDs, because several have been shown to be good substrates for P-gp, it is likely that fetal concentrations will be influenced by levels of P-gp expression in the placenta.

MRP1 and 2, ABCC1 and 2. The first member of the MRP family, MRP1, was cloned from an MDR lung cancer cell line (H69AR), which did not show increased expression of P-gp (46). Subsequently, a further eight or nine MRP genes have been identified. Of these, however, MRP1 and 2 remain the best characterized and have been demonstrated to play a significant role in protecting an organism from drugs, xenoand endobiotics.

There is considerable overlap in the spectrum of drugs to which MRP1 and 2 confer resistance, and this also overlaps with P-gp. However, unlike P-gp, MRP1 and 2 have been shown to efflux drugs such as vincristine and daunorubicin through a cotransport mechanism with reduced glutathione. Furthermore, these proteins have been shown to efflux glutathione, glucuronide, and sulfate conjugates of both xeno- and endobiotics.

MRP1 is expressed in most tissues throughout the body with relatively high levels found at the blood-brain barrier, blood-testes barrier, placenta, lungs, kidneys, skeletal muscle, spleen, and mononuclear cells and relatively low levels in the liver (47). In most tissues, MRP1 is localized to the basolateral cell membrane. In the placenta, MRP1 is expressed throughout gestation showing a fourfold increase between first trimester and term (48). Localized predominantly to the fetal blood vessel endothelial cells (Fig. 1B), it has been proposed to limit entry of xenobiotics such as AEDs into the fetal circulation,

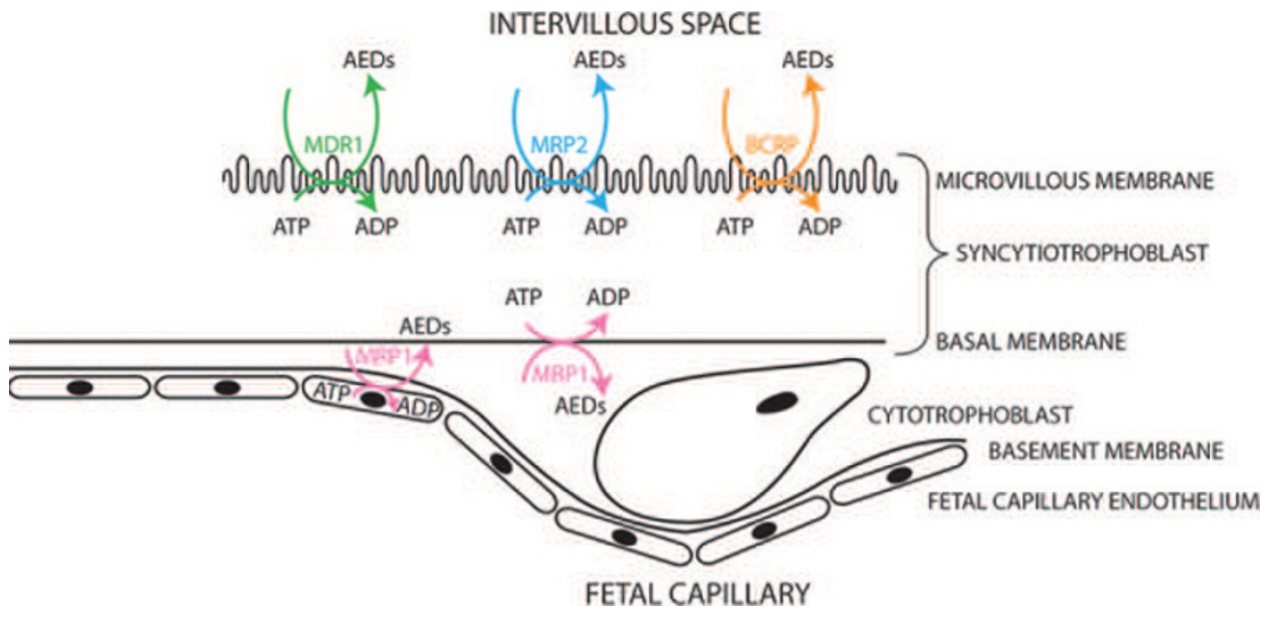

Figure 2. Schematic of placental localization and function of MDRPs. ATP hydrolysis drives the efflux of AEDs. 
while allowing excretion of conjugated waste products into the maternal circulation (8). MRP1 is also found on the basal surface of the syncytiotrophoblast, where it is suggested to prevent the accumulation of xenobiotics in the syncytiotrophoblast itself (39).

MRP2 has a more restricted tissue distribution than MRP1 and is found in the liver, kidney, small intestine, colon, gallbladder, lung, and placenta. It is consistently localized to the apical membrane. Within the placenta, MRP2 expression has been shown to increase with gestational age (49). At term, high levels of MRP2 expression have been reported on the microvillous membrane (8) and have been proposed to protect the fetus from glutathione, glucuronide, and sulfate conjugates of many drug metabolites, xenobiotics, and endogenous toxins such as bilirubin. Its importance in blood tissue barriers has been demonstrated in knockout mice, which show increased chemosensitivity (50).

$\boldsymbol{B C R P}, \boldsymbol{A B C G}$. BCRP was first described in an atypically MDR breast cancer cell line (MCF7), which did not overexpress MDR1 or MRP1 (51). BCRP is expressed in a variety of tissues including the liver, intestine, blood-brain barrier, and placenta. In polarized cells, it localizes to the apical membrane (52). BCRP confers resistance to a wide variety of drugs and xenobiotics and shows a considerable overlap in substrate specificity with MDR1 and MRP1 and 2. Once again, a protective role has been clearly demonstrated for BCRP in knockout mice. These animals are viable, healthy, and fertile; however, as with MDR1 knockouts, they show an increased sensitivity to pharmacological agents and xenobiotics. For instance, BCRP knockout mice develop severe phototoxic lesions on light-exposed skin due to cellular accumulation of the chlorophyll breakdown product pheophorbide (53). Similarly, excretion of the dietary carcinogen 2-amino-1-methyl6-phenylimidazo [4,5-b]pyridine (PhIP) is reduced by $75 \%$ in BCRP knockout mice (54).

In the placenta, BCRP is highly expressed throughout gestation, with a 10-fold higher expression at term than that of MDR1 (55). In isolated trophoblast cells, BCRP expression has been shown to increase with differentiation (56). BCRP is primarily localized to the MVM of the syncytiotrophoblast, with some expression observed in the fetal vessels (Fig. 1C) (55). A protective role for BCRP has been confirmed in mice in which topotecan and the BCRP inhibitor GF120918 were administered to pregnant females. Several hours after administration, the level of topotecan in fetal plasma was 3.2-fold higher in fetuses pretreated with GF120918 versus controls (57).

There is therefore abundant evidence that these MDRPs play an important role in fetal protection from drugs and xenobiotics present in maternal plasma. Any factor that reduces functional expression of these proteins in the placenta would therefore increase fetal exposure and result in increased susceptibility to adverse effects resulting from exposure to such compounds.

\section{Polymorphisms}

Naturally occurring genetic variations causing differences in expression of transport proteins are likely to be an impor- tant source for the interindividual variability in pharmacokinetics and pharmacodynamics of many drugs. Recently, single nucleotide polymorphisms (SNPs) in the MDR transporters have received significant attention as potential determinants of variability in drug absorption, distribution, excretion, and thus efficacy of substrate drugs. With respect to FACS, the effects that polymorphisms have on placental expression of these transporters will undoubtedly contribute to fetal susceptibility.

MDR1. The first systematic screen of MDR1 by Hoffmeyer et al. (58) identified 15 SNPs of which one, a synonymous mutation in exon 26 (C3435T), was associated with a twofold decrease in protein expression in individuals homozygous for the $\mathrm{T}$ allele. This SNP has become the most commonly studied, and many contradictory effects of the $\mathrm{T}$ allele have been reported (59). The C3435T SNP occurs in a noncoding, nonregulatory region of the MDR1 gene; therefore, the mechanism by which it influences $\mathrm{P}$-gp expression is obscure. A discussion of potential mechanisms is presented by Schwab et al. (60) and includes linkage of the C3435T SNP to other SNPs in the MDR1 gene and effects on RNA stability and splicing. Several studies have shown linkage disequilibrium between the C3435T SNP and other SNPs in the MDR1 gene. These include a synonymous SNP in exon 12 (C1236T) and a nonsynonymous SNP in exon 21 (G2677T/A). As a result of these associations, several groups have performed haplotype analysis: Kroetz et al. (61) described 48 SNPs in the MDR1 gene and have shown significant linkage disequilibrium across the entire gene. This group described 64 statistically inferred haplotypes, 14 of which have the C3435T allele. Tang et al. (62) report the first haplotype profiling using computational algorithms. Their data indicate strong linkage disequilibrium between the 3435 SNP and an unobserved causal SNP. Recently Wang et al. (63) provided evidence that the 3435C allele results in higher levels of mRNA as a result of increasing RNA stability, suggesting that this is one mechanism by which the silent C3435T polymorphism could have its effect. The number of SNPs reported in the MDR1 gene continues to increase, and a useful summary is provided by Lepper et al. (59).

With respect to AEDs, there have been several reports in recent years that suggest that polymorphisms in MDR1 may influence plasma levels of AEDs and correlate with multidrugresistant epilepsy. Kerb et al. (64) report that the CC genotype at position 3435 is more common in individuals with low phenytoin levels, whereas Siddiqui et al. (65) report that patients with drug-resistant epilepsy are more likely to have the CC genotype at position 3435 than the TT genotype. More recently, Seo et al. (66) report that the frequency of the T-T-T haplotype at C1236T, G2677T/A, and C3435T was significantly higher in drug-resistant compared with drug-responsive Japanese patients.

Only two studies to date have looked at the effect of polymorphisms on placental $\mathrm{P}$-gp expression. Tanabe et al. (67) report reduced expression of MDR1 in individuals expressing the G2677(A,T) and /or T-129C alleles, whereas Hitzel et al. (68) report reduced expression of placental P-gp in individuals homozygous for the 3435T and 2677T alleles.

MRPS. Although polymorphisms of the MRP1 gene have been reported, their effect on protein expression and function 
is still uncertain (50). Ito et al. (69) detected 16 naturally occurring SNPs in the MRP1 gene, four of which are associated with amino acid substitutions. The G2012T SNP in exon 16 results in a Gly-Val substitution but results in no obvious functional changes in protein expression or function (70). In contrast, the G1299T SNP in exon10 results in an Arg-Ser substitution, which in turn results in decreased transport of several organic anions but increased doxorubicin resistance (71). The G128C SNP in exon 2 results in a Cys-Ser substitution, which gives poor localization of the protein, resulting in decreased resistance to sodium arsenite and vincristine (72). Thus, none of the SNPs reported to date result in a complete loss of expression or function of the protein but rather moderate its substrate affinity.

Mutations in the MRP2 gene have been identified in patients with Dubin-Johnson syndrome, which is characterized by a mild conjugated hyperbilirubinemia. In these patients, loss of MRP2 function results in decreased excretion of these conjugates (50).To date, only one study observed the effect of MRP2 SNPs on placental protein expression. Meyer zu Schwabedissen et al. (49) demonstrated that the G1249A polymorphism resulted in a significant decrease in placental MRP2 mRNA expression in preterm placentas. This lower level of MRP2 expression in early-gestation placentas could result in greater exposure to drugs such as the AEDs at a time when the fetus is more susceptible to teratogenesis and could potentially therefore be involved in the MCMs sometimes observed with AED exposure.

BCRP. To date, more than 40 coding SNPs have been reported in the BCRP gene and Lepper et al. (59) provide a comprehensive list of the 43 most common. Of these, the C421A variant in exon 5 results in decreased BCRP expression (73) and also reduced ATPase activity of the mutant protein (74). G34A in exon 2 results in poor localization of the protein and a resultant decrease in efflux activity (75) and a third less common SNP, the C376T polymorphism in exon 4 substitutes a stop codon for Gln at position126, resulting in no BCRP expression. Only one study of placental BCRP polymorphisms has been reported to date (76), and it demonstrated significantly lower BCRP expression in individuals homozygous for the A421 allele compared with C421.

\section{CONCLUSION}

Fetal genotype with respect to these multidrug-resistance transporters will undoubtedly be important in determining fetal susceptibility to AEDs and any other drug or xenobiotic present in maternal plasma. The mechanisms determining interindividual variations in expression of these proteins are worthy of extensive investigation because identification of susceptible genotypes would add a further dimension to the counseling, which has been recommended for all epileptic women of child-bearing age.

\section{REFERENCES}

1. Morrow J, Russell A, Guthrie E, Parsons L, Robertson I, Waddell R, Irwin B, McGivern RC, Morrison PJ, Craig J 2006 Malformation risks of antiepileptic drugs in pregnancy: a prospective study from the UK Epilepsy and Pregnancy Register. J Neurol Neurosurg Psychiatry 77:193-198
2. Adab N, Tudur SC, Vinten J, Williamson P, Winterbottom J 2004 Common antiepileptic drugs in pregnancy in women with epilepsy. Cochrane Database Syst Rev 3:CD004848

3. Ornoy A 2006 Neuroteratogens in man: an overview with special emphasis on the teratogenicity of antiepileptic drugs in pregnancy. Reprod Toxicol 22:214-226

4. Meador KJ, Baker GA, Finnell RH, Kalayjian LA, Liporace JD, Loring DW, Mawer G, Pennell PB, Smith JC, Wolff MC 2006 In utero antiepileptic drug exposure: fetal death and malformations. Neurology 67:407-412

5. Viinikainen K, Heinonen S, Eriksson K, Kalviainen R 2006 Community-based, prospective, controlled study of obstetric and neonatal outcome of 179 pregnancies in women with epilepsy. Epilepsia 47:186-192

6. Atkinson DE, Boyd RD, Sibley CP 2006 Placental transfer. In: Neill JD (ed) Knobil and Neill's Physiology of Reproduction. Elsevier, pp. 2787-2846

7. Atkinson DE, Sibley CP, Fairbairn LJ, Greenwood SL 2006 MDR1 P-gp expression and activity in intact human placental tissue; upregulation by retroviral transduction. Placenta 27:707-714

8. St-Pierre MV, Serrano MA, Macias RI, Dubs U, Hoechli M, Lauper U, Meier PJ, Marin JJ 2000 Expression of members of the multidrug resistance protein family in human term placenta. Am J Physiol Regul Integr Comp Physiol 279:R1495-R1503

9. Ganapathy V, Prasad PD, Ganapathy ME, Leibach FH 2000 Placental transporters relevant to drug distribution across the maternal-fetal interface. J Pharmacol Exp Ther 294:413-420

10. Doyle LA, Ross DD 2003 Multidrug resistance mediated by the breast cancer resistance protein BCRP (ABCG2). Oncogene 22:7340-7358

11. Dean JC, Hailey H, Moore SJ, Lloyd DJ, Turnpenny PD, Little J 2002 Long term health and neurodevelopment in children exposed to antiepileptic drugs before birth. J Med Genet 39:251-259

12. Adab N, Kini U, Vinten J, Ayres J, Baker G, Clayton-Smith J, Coyle H, Fryer A, Gorry J, Gregg J, Mawer G, Nicolaides P, Pickering L, Tunnicliffe L, Chadwick DW 2004 The longer term outcome of children born to mothers with epilepsy. J Neurol Neurosurg Psychiatry 75:1575-1583

13. EURAP Study Group 2006 Seizure control and treatment in pregnancy: observations from the EURAP epilepsy pregnancy registry. Neurology 66:354-360

14. Richmond JR, Krishnamoorthy P, Andermann E, Benjamin A 2004 Epilepsy and pregnancy: an obstetric perspective. Am J Obstet Gynecol 190:371-379

15. Pennell PB 2002 Pregnancy in the woman with epilepsy: maternal and fetal outcomes. Semin Neurol 22:299-308

16. Wide K, Winbladh B, Kallen B 2004 Major malformations in infants exposed to antiepileptic drugs in utero, with emphasis on carbamazepine and valproic acid: a nation-wide, population-based register study. Acta Paediatr 93:174-176

17. Artama M, Auvinen A, Raudaskoski T, Isojarvi I, Isojarvi J 2005 Antiepileptic drug use of women with epilepsy and congenital malformations in offspring. Neurology 64:1874-1878

18. Holmes LB, Wyszynski DF, Lieberman E 2004 The AED (antiepileptic drug) pregnancy registry: a 6-year experience. Arch Neurol 61:673-678

19. Vajda FJ, Eadie MJ 2005 Maternal valproate dosage and foetal malformations. Acta Neurol Scand 112:137-143

20. Cunnington M, Tennis P 2005 Lamotrigine and the risk of malformations in pregnancy. Neurology 64:955-960

21. Samren EB, van Duijn CM, Christiaens GC, Hofman A, Lindhout D 1999 Antiepileptic drug regimens and major congenital abnormalities in the offspring. Ann Neurol 46:739-746

22. Kaneko S, Battino D, Andermann E, Wada K, Kan R, Takeda A, Nakane Y, Ogawa Y, Avanzini G, Fumarola C, Granata T, Molteni F, Pardi G, Minotti L, Canger R, Dansky L, Oguni M, Lopes-Cendas I, Sherwin A, Andermann F, Seni MH, Okada M, Teranishi T 1999 Congenital malformations due to antiepileptic drugs. Epilepsy Res 33:145-158

23. Mawer G, Clayton-Smith J, Coyle H, Kini U 2002 Outcome of pregnancy in women attending an outpatient epilepsy clinic: adverse features associated with higher doses of sodium valproate. Seizure 11:512-518

24. Padmanabhan R, Abdulrazzaq YM, Bastaki SM, Shafiullah M, Chandranath SI 2003 Experimental studies on reproductive toxicologic effects of lamotrigine in mice. Birth Defects Res B Dev Reprod Toxicol 68:428-438

25. Gaily E, Granstrom ML 1992 Minor anomalies in children of mothers with epilepsy. Neurology 42:128-131

26. Kini U, Adab N, Vinten J, Fryer A, Clayton-Smith J 2006 Dysmorphic features: an important clue to the diagnosis and severity of fetal anticonvulsant syndromes. Arch Dis Child Fetal Neonatal Ed 91:F90-F95

27. Holmes LB, Harvey EA, Coull BA, Huntington KB, Khoshbin S, Hayes AM, Ryan LM 2001 The teratogenicity of anticonvulsant drugs. N Engl J Med 344:1132-1138

28. Adab N, Jacoby A, Smith D, Chadwick D 2001 Additional educational needs in children born to mothers with epilepsy. J Neurol Neurosurg Psychiatry 70:15-21

29. Gaily E, Kantola-Sorsa E, Hiilesmaa V, Isoaho M, Matila R, Kotila M, Nylund T, Bardy A, Kaaja E, Granstrom ML 2004 Normal intelligence in children with prenatal exposure to carbamazepine. Neurology 62:28-32

30. Eriksson K, Viinikainen K, Monkkonen A, Aikia M, Nieminen P, Heinonen S, Kalviainen R 2005 Children exposed to valproate in utero-population based evaluation of risks and confounding factors for long-term neurocognitive development. Epilepsy Res 65:189-200

31. Loscher W, Potschka H 2002 Role of multidrug transporters in pharmacoresistance to antiepileptic drugs. J Pharmacol Exp Ther 301:7-14

32. Kwan P, Brodie MJ 2005 Potential role of drug transporters in the pathogenesis of medically intractable epilepsy. Epilepsia 46:224-235

33. Tishler DM, Weinberg KI, Hinton DR, Barbaro N, Annett GM, Raffel C 1995 MDR1 gene expression in brain of patients with medically intractable epilepsy. Epilepsia 36:1-6 
34. Sisodiya SM, Lin WR, Harding BN, Squier MV, Thom M 2002 Drug resistance in epilepsy: expression of drug resistance proteins in common causes of refractory epilepsy. Brain 125:22-31

35. Marchi N, Hallene KL, Kight KM, Cucullo L, Moddel G, Bingaman W, Dini G, Vezzani A, Janigro D 2004 Significance of MDR1 and multiple drug resistance in refractory human epileptic brain. BMC Med 2:37-47

36. Potschka H, Fedrowitz M, Loscher W 2002 P-Glycoprotein-mediated efflux of phenobarbital, lamotrigine, and felbamate at the blood-brain barrier: evidence from microdialysis experiments in rats. Neurosci Lett 327:173-176

37. Potschka H, Fedrowitz M, Loscher W 2003 Multidrug resistance protein MRP2 contributes to blood-brain barrier function and restricts antiepileptic drug activity. J Pharmacol Exp Ther 306:124-131

38. Sun M, Kingdom J, Baczyk D, Lye SJ, Matthews SG, Gibb W 2006 Expression of the multidrug resistance P-glycoprotein, (ABCB1 glycoprotein) in the human placenta decreases with advancing gestation. Placenta 27:602-609

39. Atkinson DE, Greenwood SL, Sibley CP, Glazier JD, Fairbairn LJ 2003 Role of MDR1 and MRP1 in trophoblast cells, elucidated using retroviral gene transfer. Am J Physiol Cell Physiol 285:C584-C591

40. Nakamura Y, Ikeda S, Furukawa T, Sumizawa T, Tani A, Akiyama S, Nagata Y 1997 Function of P-glycoprotein expressed in placenta and mole. Biochem Biophys Res Commun 235:849-853

41. Ushigome F, Takanaga H, Matsuo H, Yanai S, Tsukimori K, Nakano H, Uchiumi T, Nakamura T, Kuwano M, Ohtani H, Sawada Y 2000 Human placental transport of vinblastine, vincristine, digoxin and progesterone: contribution of P-glycoprotein. Eur J Pharmacol 408:1-10

42. Ushigome F, Koyabu N, Satoh S, Tsukimori K, Nakano H, Nakamura T, Uchiumi T, Kuwano M, Ohtani H, Sawada Y 2003 Kinetic analysis of P-glycoproteinmediated transport by using normal human placental brush-border membrane vesicles. Pharm Res 20:38-44

43. Molsa M, Heikkinen T, Hakkola J, Hakala K, Wallerman O, Wadelius M, Wadelius C, Laine K 2005 Functional role of P-glycoprotein in the human blood-placental barrier. Clin Pharmacol Ther 78:123-131

44. Smit JW, Huisman MT, van Tellingen O, Wiltshire HR, Schinkel AH 1999 Absence or pharmacological blocking of placental P-glycoprotein profoundly increases fetal drug exposure. J Clin Invest 104:1441-1447

45. Lankas GR, Wise LD, Cartwright ME, Pippert T, Umbenhauer DR 1998 Placental P-glycoprotein deficiency enhances susceptibility to chemically induced birth defects in mice. Reprod Toxicol 12:457-463

46. Cole SP, Bhardwaj G, Gerlach JH, Mackie JE, Grant CE, Almquist KC, Stewart AJ, Kurz EU, Duncan AM, Deeley RG 1992 Overexpression of a transporter gene in a multidrug-resistant human lung cancer cell line. Science 258:1650-1654

47. Cole SP, Deeley RG 1998 Multidrug resistance mediated by the ATP-binding cassette transporter protein MRP. Bioessays 20:931-940

48. Pascolo L, Fernetti C, Pirulli D, Crovella S, Amoroso A, Tiribelli C 2003 Effects of maturation on RNA transcription and protein expression of four MRP genes in human placenta and in BeWo cells. Biochem Biophys Res Commun 303:259-265

49. Meyer zu Schwabedissen HE, Jedlitschky G, Gratz M, Haenisch S, Linnemann K, Fusch C, Cascorbi I, Kroemer HK 2005 Variable expression of MRP2 (ABCC2) in human placenta: influence of gestational age and cellular differentiation. Drug Metab Dispos 33:896-904

50. Conseil G, Deeley RG, Cole SP 2005 Polymorphisms of MRP1 (ABCC1) and related ATP-dependent drug transporters. Pharmacogenet Genomics 15:523-533

51. Doyle LA, Yang W, Abruzzo LV, Krogmann T, Gao Y, Rishi AK, Ross DD 1998 A multidrug resistance transporter from human MCF-7 breast cancer cells. Proc Natl Acad Sci U S A 95:15665-15670

52. Maliepaard M, Scheffer GL, Faneyte IF, van Gastelen MA, Pijnenborg AC, Schinkel AH, van De Vijver MJ, Scheper RJ, Schellens JH 2001 Subcellular localization and distribution of the breast cancer resistance protein transporter in normal human tissues. Cancer Res 61:3458-3464

53. Jonker JW, Buitelaar M, Wagenaar E, Van Der Valk MA, Scheffer GL, Scheper RJ, Plosch T, Kuipers F, Elferink RP, Rosing H, Beijnen JH, Schinkel AH 2002 The breast cancer resistance protein protects against a major chlorophyll-derived dietary phototoxin and protoporphyria. Proc Natl Acad Sci USA 99:15649-15654

54. van Herwaarden AE, Jonker JW, Wagenaar E, Brinkhuis RF, Schellens JH, Beijnen JH, Schinkel AH 2003 The breast cancer resistance protein (Bcrp1/Abcg2) restricts exposure to the dietary carcinogen 2-amino-1-methyl-6-phenylimidazo[4,5b]pyridine. Cancer Res 63:6447-6452

55. Ceckova M, Libra A, Pavek P, Nachtigal P, Brabec M, Fuchs R, Staud F 2006 Expression and functional activity of breast cancer resistance protein (BCRP, ABCG2) transporter in the human choriocarcinoma cell line BeWo. Clin Exp Pharmacol Physiol 33:58-65

56. Evseenko DA, Paxton JW, Keelan JA 2006 ABC drug transporter expression and functional activity in trophoblast-like cell lines and differentiating primary trophoblast. Am J Physiol Regul Integr Comp Physiol 290:R1357-R1365

57. Jonker JW, Smit JW, Brinkhuis RF, Maliepaard M, Beijnen JH, Schellens JH, Schinkel AH 2000 Role of breast cancer resistance protein in the bioavailability and fetal penetration of topotecan. J Natl Cancer Inst 92:1651-1656

58. Hoffmeyer S, Burk O, von Richter O, Arnold HP, Brockmoller J, Johne A, Cascorbi I, Gerloff T, Roots I, Eichelbaum M, Brinkmann U 2000 Functional polymorphisms of the human multidrug-resistance gene: multiple sequence variations and correlation of one allele with P-glycoprotein expression and activity in vivo. Proc Natl Acad Sci USA 97:3473-3478
59. Lepper ER, Nooter K, Verweij J, Acharya MR, Figg WD, Sparreboom A 2005 Mechanisms of resistance to anticancer drugs: the role of the polymorphic $\mathrm{ABC}$ transporters ABCB1 and ABCG2. Pharmacogenomics 6:115-138

60. Schwab M, Eichelbaum M, Fromm MF 2003 Genetic polymorphisms of the human MDR1 drug transporter. Annu Rev Pharmacol Toxicol 43:285-307

61. Kroetz DL, Pauli-Magnus C, Hodges LM, Huang CC, Kawamoto M, Johns SJ, Stryke D, Ferrin TE, DeYoung J, Taylor T, Carlson EJ, Herskowitz I, Giacomini KM, Clark AG 2003 Sequence diversity and haplotype structure in the human ABCB1 (MDR1, multidrug resistance transporter) gene. Pharmacogenetics 13:481494

62. Tang K, Ngoi SM, Gwee PC, Chua JM, Lee EJ, Chong SS, Lee CG 2002 Distinct haplotype profiles and strong linkage disequilibrium at the MDR1 multidrug transporter gene locus in three ethnic Asian populations. Pharmacogenetics $12: 437-450$

63. Wang D, Johnson AD, Papp AC, Kroetz DL, Sadee W 2005 Multidrug resistance polypeptide 1 (MDR1, ABCB1) variant $3435 \mathrm{C}>\mathrm{T}$ affects mRNA stability. Pharmacogenet Genomics 15:693-704

64. Kerb R, Aynacioglu AS, Brockmoller J, Schlagenhaufer R, Bauer S, Szekeres T, Hamwi A, Fritzer-Szekeres M, Baumgartner C, Ongen HZ, Guzelbey P, Roots I, Brinkmann U 2001 The predictive value of MDR1, CYP2C9, and CYP2C19 polymorphisms for phenytoin plasma levels. Pharmacogenomics J 1:204-210

65. Siddiqui A, Kerb R, Weale ME, Brinkmann U, Smith A, Goldstein DB, Wood NW, Sisodiya SM 2003 Association of multidrug resistance in epilepsy with a polymorphism in the drug-transporter gene ABCB1. N Engl J Med 348:1442-1448

66. Seo T, Ishitsu T, Ueda N, Nakada N, Yurube K, Ueda K, Nakagawa K 2006 ABCB1 polymorphisms influence the response to antiepileptic drugs in Japanese epilepsy patients. Pharmacogenomics 7:551-561

67. Tanabe M, Ieiri I, Nagata N, Inoue K, Ito S, Kanamori Y, Takahashi M, Kurata Y, Kigawa J, Higuchi S, Terakawa N, Otsubo K 2001 Expression of P-glycoprotein in human placenta: relation to genetic polymorphism of the multidrug resistance (MDR)-1 gene. J Pharmacol Exp Ther 297:1137-1143

68. Hitzl M, Schaeffeler E, Hocher B, Slowinski T, Halle H, Eichelbaum M, Kaufmann P, Fritz P, Fromm MF, Schwab M 2004 Variable expression of P-glycoprotein in the human placenta and its association with mutations of the multidrug resistance 1 gene (MDR1, ABCB1). Pharmacogenetics 14:309-318

69. Ito S, Ieiri I, Tanabe M, Suzuki A, Higuchi S, Otsubo K 2001 Polymorphism of the $\mathrm{ABC}$ transporter genes, MDR1, MRP1 and MRP2/cMOAT, in healthy Japanese subjects. Pharmacogenetics 11:175-184

70. Conrad S, Kauffmann HM, Ito K, Deeley RG, Cole SP, Schrenk D 2001 Identification of human multidrug resistance protein 1 (MRP1) mutations and characterization of a G671V substitution. J Hum Genet 46:656-663

71. Conrad S, Kauffmann HM, Ito K, Leslie EM, Deeley RG, Schrenk D, Cole SP 2002 A naturally occurring mutation in MRP1 results in a selective decrease in organic anion transport and in increased doxorubicin resistance. Pharmacogenetics 12:321330

72. Leslie EM, Letourneau IJ, Deeley RG, Cole SP 2003 Functional and structural consequences of cysteine substitutions in the $\mathrm{NH} 2$ proximal region of the human multidrug resistance protein 1 (MRP1/ABCC1). Biochemistry 42:5214-5224

73. Imai Y, Nakane M, Kage K, Tsukahara S, Ishikawa E, Tsuruo T, Miki Y, Sugimoto $\mathrm{Y} 2002$ C421A polymorphism in the human breast cancer resistance protein gene is associated with low expression of Q141K protein and low-level drug resistance. Mol Cancer Ther 1:611-616

74. Morisaki K, Robey RW, Ozvegy-Laczka C, Honjo Y, Polgar O, Steadman K, Sarkadi B, Bates SE 2005 Single nucleotide polymorphisms modify the transporter activity of ABCG2. Cancer Chemother Pharmacol 56:161-172

75. Mizuarai S, Aozasa N, Kotani H 2004 Single nucleotide polymorphisms result in impaired membrane localization and reduced ATPase activity in multidrug transporter ABCG2. Int J Cancer 109:238-246

76. Kobayashi D, Ieiri I, Hirota T, Takane H, Maegawa S, Kigawa J, Suzuki H, Nanba E, Oshimura M, Terakawa N, Otsubo K, Mine K, Sugiyama Y 2005 Functional assessment of ABCG2 (BCRP) gene polymorphisms to protein expression in human placenta. Drug Metab Dispos 33:94-10

77. Matalon S, Schechtman S, Goldzweig G, Ornoy A 2002 The teratogenic effect of carbamazepine: a meta-analysis of 1255 exposures. Reprod Toxicol 16:9-17

78. Wyszynski DF, Nambisan M, Surve T, Alsdorf RM, Smith CR, Holmes LB 2005 Increased rate of major malformations in offspring exposed to valproate during pregnancy. Neurology 64:961-965

79. Canger R, Battino D, Canevini MP, Fumarola C, Guidolin L, Vignoli A, Mamoli D, Palmieri C, Molteni F, Granata T, Hassibi P, Zamperini P, Pardi G, Avanzini G 1999 Malformations in offspring of women with epilepsy: a prospective study. Epilepsia 40:1231-1236

80. Kaaja E, Kaaja R, Hiilesmaa V 2003 Major malformations in offspring of women with epilepsy. Neurology 60:575-579

81. Sabers A, Dam M, Rogvi-Hansen B, Boas J, Sidenius P, Laue Friis M, Alving J, Dahl M, Ankerhus J, Mouritzen Dam A 2004 Epilepsy and pregnancy: lamotrigine as main drug used. Acta Neurol Scand 109:9-13

82. Tomson T, Battino D, Bonizzoni E, Craig J, Lindhout D, Perucca E, Sabers A, Vajda F 2004 EURAP: an international registry of antiepileptic drugs and pregnancy. Epilepsia 45:1463-1464

83. Diav-Citrin O, Shechtman S, Arnon J, Ornoy A 2001 Is carbamazepine teratogenic? A prospective controlled study of 210 pregnancies. Neurology 57:321-324 